\title{
High Density Deletion Mapping of Bladder Cancer Localizes the Putative Tumor Suppressor Gene Between Loci D8S504 and D8S264 at Chromosome 8p23.3
}

\author{
Michael Muscheck, Farkas Sükösd, Tamas Pesti, and Gyula Kovacs \\ Laboratory of Molecular Oncology, Department of Urology, Ruprecht-Karls-University, Heidelberg, Germany
}

SUMMARY: Deletion of chromosome $8 p$ is associated with the progression of bladder cancer. To identify the putative tumor suppressor gene locus we have analyzed 145 bladder cancers with 12 microsatellite markers for allelic changes at the chromosome 8p23.3 region. We mapped the smallest overlapping deletion to approximately $0.7 \mathrm{cM}$ genetic distance between loci D8S504 and D8S264. Allelic changes at this region occurred in $75(52 \%)$ of the 145 tumors. We found a significant correlation between alterations at chromosome 8p23.3 and the tumor grade. The correlation between genetic changes and tumor stage reflected the distribution of tumors of different grades in each pathologic stage. (Lab Invest 2000, 80:1089-1093).

$P_{\mathrm{sen}}^{\mathrm{ras}}$ revious DNA studies detected allelic changes at several chromosomal regions in transitional cell carcinomas (TCC) of the urinary bladder (Knowles, 1999). Because loss of heterozygosity (LOH) at chromosome $9 p$ occurs in $80 \%$ to $90 \%$ of TCC, it is believed to be an initial genetic event (Baud et al, 1998; Orlow et al, 1994; Stadler et al, 1994). Alteration of the chromosome $8 p$ region was shown in $22 \%$ to $54 \%$ of bladder TCC in RFLP, microsatellite, and comparative genomic hybridization (CGH) studies (Hovey et al, 1998; Kallioniemi et al, 1995; Knowles et al, 1993; Ohgaki et al, 1999; Richter et al, 1997, 1998, 1999; Simon et al, 1998; Takle and Knowles, 1996). When genetic changes and tumor stages were evaluated, loss of chromosome $8 p$ sequences showed an association with invasive growth of TCC. Fluorescence in situ hybridization (FISH) analysis by using bacterial artificial chromosome (BAC) clones found a correlation between loss of signal at the chromosome 8 p22 band and tumor progression (Wagner et al, 1997). Recently, the putative tumor suppressor gene was mapped to an approximately $1 \mathrm{Mb}$ region on chromosome 8p22 (Ohgaki et al, 1999). Other studies showed deletion of the entire chromosome $8 p$ or large regions encompassing several chromosomal bands in TCC.

In a pilot study, we performed deletion mapping of 56 bladder cancers with 14 microsatellite markers

Received March 14, 2000.

This work was supported by a grant from the German Research Council (Ko 841/13-1).

Address reprint requests to: Dr. G. Kovacs, Laboratory of Molecular Oncology, Department of Urology, Ruprecht-Karls University, Im Neuenheimer Feld 365, Room 002, D-69120 Heidelberg, Germany. Fax: 496221 564634; E-mail: gyula.kovacs@urz.uni-heidelberg.de covering the entire chromosome $8 \mathrm{p}$. We delineated an approximately $4 \mathrm{cM}$ region of $\mathrm{LOH}$ between loci D8S264 and D8S262 on chromosome 8p23.3 (unpublished data). Allelic changes at this region were associated with grade and stage of TCC. Deletion mapping studies on other types of cancer have also suggested that this chromosomal region may harbor a tumor suppressor gene (Ishwad et al, 1999; Perinchery et al, 1999; Pineau et al, 1999; Scholnick et al, 1996; Wright et al, 1998; Wu et al, 1997). To delineate the putative tumor suppressor gene locus, we analyzed 145 bladder cancers for 12 microsatellite loci at chromosome 8p23.3. We defined a smallest overlapping region of approximately $0.7 \mathrm{cM}$ genetic distance between loci D8S504 and D8S264 and we found a correlation between $\mathrm{LOH}$ and tumor grade.

\section{Results}

Defining the Tumor Gene Locus at Chromosome 8p23.3

Microsatellite loci and their position are shown in Figure 1. We detected $\mathrm{LOH}$ at all informative loci at chromosome 8p23.3 in 63 of 145 bladder cancers. Terminal deletions were seen in cases $36,115,167$, 189,217 , and 1205, whereas interstitial deletions by retention of heterozygosity for locus D8S504 were detected in tumors 14, 55, 116, 180, 1221-4, and 1221-5. The smallest interstitial deletion was seen in tumors 1221-4 and 1221-5. Both showed LOH at locus AFMB322ZH9 and retention of heterozygosity at flanking loci D8S504 and D8S264 (Fig. 2). The genetic distance between the two loci is estimated to be approximately $0.7 \mathrm{cM}$ in the GeneMap'99 (http:// www.ncbi.nlm.nih.gov/genemap/). LOH involving this small region was seen in 75 (52\%) of the 145 bladder cancers examined. 


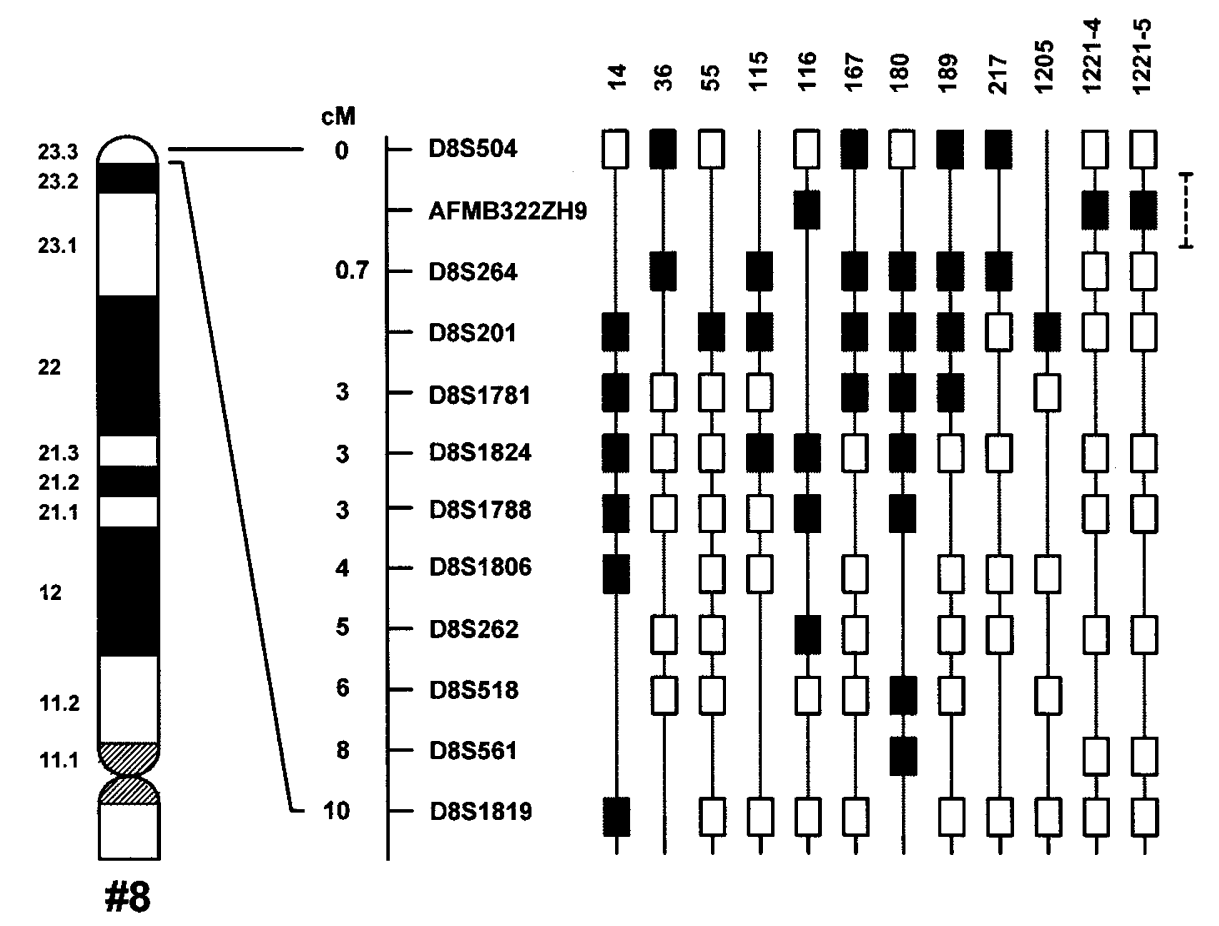

Figure 1.

Allelic changes at chromosome 8p23.3 in 12 transitional cell carcinomas (TCC) showing partial deletions. The location of microsatellite markers are shown on the left. A vertical bar on the right indicates the smallest overlapping deletion. Open square $=$ retention of both alleles without allelic imbalance; filled square $=$ loss of heterozygosity; no square = homozygous loci.

\section{LOH at 8p23.3 and Pathologic Data}

We evaluated the frequency of $\mathrm{LOH}$ at the putative tumor suppressor gene locus in 145 TCC of the urinary bladder of different histologic stages and grades (Table 1). We found a strong correlation between $\mathrm{LOH}$ and tumor grade. Only $5(13 \%)$ of the 39 G1 bladder cancers had an $\mathrm{LOH}$ at chromosome $8 \mathrm{p} 23.3$, whereas $32(53 \%)$ of the 60 grade 2 TCC and $38(82 \%)$ of the 46 grade 3 TCC showed this genetic change. $\mathrm{LOH}$ at chromosome 8p23.3 occurred only in 21 (29\%) of 72 superficially growing $(\mathrm{pTa})$ tumors, whereas $64 \%$ of pT1, $81 \%$ of pT2, and $76 \%$ of pT3-4 TCC displayed this genetic change. Altogether, $\mathrm{LOH}$ at chromosome 8 p23.3 was seen in $74 \%$ of invasive growing bladder cancers. The high frequency of $\mathrm{LOH}$ in invasive TCC is associated with the distribution of tumors of different grades within each stage. In our study, all but one of the 72 noninvasive (pTa) TCC showed grade 1 or 2 . The early invasive tumors ( $\mathrm{pT} 1$ and $\mathrm{pT} 2$ ) displayed nearly equally nuclear grades 2 and 3 , whereas the vast majority of pT3-4 tumors showed grade 3 . We found only minimal differences in allelic changes between pTa, G2 (44\%) and pT1, G2 (53\%) tumors. These data indicate that $\mathrm{LOH}$ at chromosome 8p23.3 is primarily associated with the grade of TCC.

\section{Discussion}

We mapped a putative tumor suppressor gene locus to an approximately $0.7 \mathrm{cM}$ genetic distance between loci D8S504 and D8S264 at the terminal part of the chromosome 8p23.3 region. We found allelic changes at this region in $52 \%$ of the unbiased series of bladder cancers. Earlier, the putative tumor suppressor gene on chromosome $8 p$ was mapped to two large regions, one between loci D8S264 and D8S133 at 8p21.1-pter and another between the NFL and PLAT genes at chromosome 8p21-q11.2 in TCC (Knowles et al, 1993; Takle and Knowles, 1996). Our region is localized to the most distal part of the large region 8p21.1-pter determined by Takle and Knowles (1996). Recently, a tumor suppressor gene region was mapped to an approximately $1 \mathrm{Mb}$ interval flanked by loci D8S1135 and AFM177XB10 at chromosome 8p22 (Ohgaki et al, 1999). Thus, comprehensive deletion mapping studies on TCC suggest that chromosome $8 p$ harbors at least two tumor suppressor genes, one at $8 \mathrm{p} 22$ and another at 8p23.3.

Most deletion mapping and CGH studies suggested a correlation between chromosome $8 p$ alterations and the stage of bladder cancer. Knowles et al (1993) found $\mathrm{LOH}$ at chromosome $8 p$ in $12 \%$ of superficial (pTa) and in $32 \%$ of invasive (pT1-2) tumors. CGH analysis revealed DNA losses at chromosome 8p in only $0.7 \%$ of pTa TCC and in $32 \%$ of pT1 tumors (Richter et al, 1997). By increasing the number of cases, the same group of investigators described chromosome $8 p$ alterations in $9 \%$ and $24 \%$ of $p T a$ and pT1 tumors, respectively (Richter et al, 1998; Zhao et al, 1999). They found chromosomal imbalances at chromosome $8 p$ in $42 \%$ of pT2-4 tumors (Richter et al, 1998). Our microsatellite analysis revealed $\mathrm{LOH}$ at chromosome $8 \mathrm{p} 23.3$ in $29 \%$ of pTa, in $64 \%$ of $\mathrm{pT} 1$, and in $78 \%$ of $\mathrm{pT} 2-4$ tumors, which is 


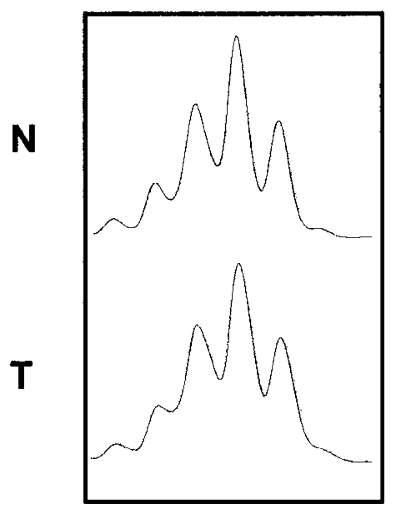

\section{D8S504}

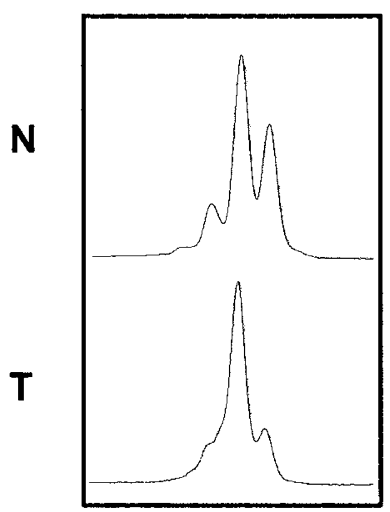

\section{AFMB322ZH9}

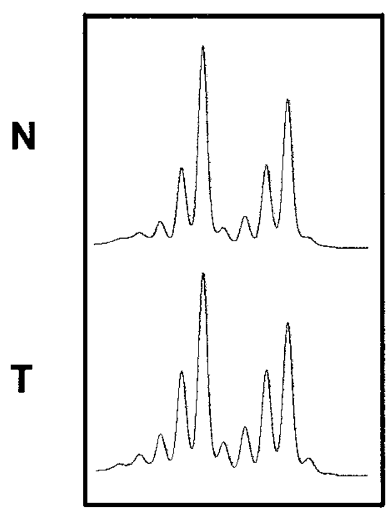

\section{D8S264}

Figure 2.

Small interstitial deletion of approximately $0.7 \mathrm{cM}$ genetic distance in TCC 1221-4. Notice the loss of heterozygosity at locus AFM322ZH9 and retention of constitutional heterozygosity without allelic imbalance at flanking loci D8S504 and D8S264. DNA from normal blood $(M)$ and tumor $(T)$ samples were used for amplification.

higher than detected in $\mathrm{CGH}$ studies. This may reflect the more precise nature of microsatellite studies compared with the limited sensitivity and resolution of $\mathrm{CGH}$. Moreover, this may explain why some of the CGH studies did not find a correlation between DNA imbalances at chromosome $8 p$ and the progression of pT1 TCC (Richter et al, 1998, 1999).

Alteration of chromosome $8 p$ has been associated with the grade of bladder cancer as well. CGH studies detected chromosome $8 p$ imbalances in $0 \%, 13 \%$, and $29 \%$ of TCC of grade 1,2, and 3, respectively (Richter et al, 1999; Zhao et al, 1999). Recently, Ohgaki et al (1999) found a significant difference in the frequency of genetic alterations at chromosome 8p22 between TCC of grades 1 and $2(26 \%)$ and of grade 3 (58\%). Our allelotyping study revealed a low frequency of $\mathrm{LOH}$ at chromosome $8 \mathrm{p} 23.3$ in grade 1 TCC (13\%) in comparison with grade 2 (53\%) and grade $3(83 \%)$ bladder cancers. We found only a slight difference between the frequency of $\mathrm{LOH}$ at chromosome 8p23.3 in pTa, G2 (44\%), and pT1, G2 (53\%) TCC. Our data indicate that $\mathrm{LOH}$ at chromosome $8 \mathrm{p} 23.3$ is primarily associated with the nuclear grade, eg, with the proliferative activity of bladder cancer. In our series of TCC, all but one noninvasive (pTa) tumor displayed grade 1 and grade 2 , whereas pT1 or pT2 TCC showed grade 2 and grade 3 , and the overwhelming majority of cancers in stage pT3-4 showed nuclear grade 3. Thus, the correlation between $\mathrm{LOH}$ at chromosome 8p23.3 and tumor stage simply reflects the distribution of TCC of different grades in each pathologic stage.

$\mathrm{LOH}$ at chromosome 8p23 was also detected in oral and oropharyngeal squamous cell carcinoma, ovarian adenocarcinoma, hepatocellular carcinoma, and prostate cancer (Ishwad et al, 1999; Perinchery et al, 1999; Pineau et al, 1999; Wright et al, 1998; Wu et al, 1997). Allelic loss at locus D8S264 showed a correlation with early tumor recurrence and shorter disease-specific survival of patients with supraglottic squamous cell carcinomas (Scholnick et al, 1996). The putative tumor suppressor gene was mapped between loci D8S264 and D8S1788 (Sunwoo et al, 1999). This region is located on the proximal site, whereas our region is on the distal site of locus D8S264. The existence of tumor suppressor gene(s) at these regions has been confirmed by microcell-mediated transfer of chromosome $8 p$ sequences into colorectal cancer cell lines that resulted in reduced tumorigenicity (Gustafson et al, 1996). To improve the results of deletion mapping and chromosomal replacement studies, cloning and analyzing the genes in a follow up study will be necessary. Sixteen putative gene fragments have already been mapped to the $0.7 \mathrm{cM}$ region between loci D8S504 and D8S264 (http://www.ncbi.nlm.nih.gov/genemap/), which will be helpful in cloning the tumor suppressor gene.

\section{Materials and Methods}

\section{Tumor Samples and DNA Extraction}

Fresh tumor tissues were obtained by transurethral resection or radical cystectomy at the Departments of Urology, Mannheim Hospital, Ruprecht-Karls-University Heidelberg and Philipps-University Marburg, Germany. For normal controls, $10 \mathrm{ml}$ of matched peripheral blood samples were taken. Part of the tumor tissue was immediately snap-frozen in liquid nitrogen and stored at $-80^{\circ} \mathrm{C}$. The histologic diagnosis according to the TNMClassification (Union Internationale Contre le Cancer) was obtained from the Departments of Pathology at both universities. This study comprised 72 tumors of pathologic stage pTa, 22 tumors of stage pT1, 16 tumors of stage pT2, and 35 tumors of stage pT3-4. Thirty-nine tumors were well-differentiated (grade 1), 60 tumors 
Table 1. LOH at Chromosome 8p23.3 and Tumor Stage/Grade

\begin{tabular}{lccccr}
\hline & \multicolumn{5}{c}{ Stage } \\
\cline { 2 - 6 } Grade & pTa & pT1 & pT2 & pT3-4 & Total \\
\hline 1 & $5 / 37(13)^{*}$ & $-/ 1$ & $-/ 1$ & - & $5 / 39(13)$ \\
2 & $15 / 34(44)$ & $7 / 13(53)$ & $6 / 7(86)$ & $4 / 6(66)$ & $32 / 60(53)$ \\
3 & $1 / 1$ & $7 / 8(87)$ & $7 / 8(87)$ & $23 / 29(79)$ & $38 / 46(83)$ \\
Total & $21 / 72(29)$ & $14 / 22(64)$ & $13 / 16(81)$ & $27 / 35(77)$ & $75 / 145(52)$ \\
\hline
\end{tabular}

${ }^{*}$ Figures in brackets indicate the percentage of $\mathrm{LOH}$.

were moderately differentiated (grade 2), and 46 tumors were poorly differentiated (grade 3).

A frozen tumor sample was placed on a plastic Petri dish, covered with $1 \mathrm{ml}$ of TE9 buffer (500 mM Tris, $\mathrm{pH}$ 9; $20 \mathrm{mM}$ EDTA; $10 \mathrm{mM} \mathrm{NaCl}$ ), and allowed to thaw. The tumor cells were then carefully scraped or pushed out to separate them from stromal tissue under an inverted microscope by a pathologist (GK) experienced in this technique. The stromal tissue was discarded. Using this method, contamination from normal cells was reduced to a minimum. Tumor cells were resuspended in $5 \mathrm{ml}$ of TE9 buffer with 1\% SDS and $0.2 \mathrm{mg} / \mathrm{ml}$ of proteinase $\mathrm{K}$, and were incubated for 3 hours at $55^{\circ} \mathrm{C}$. DNA was extracted with phenolchloroform and dissolved in TE buffer (10 mM Tris; 1 mM EDTA, pH 7.4) after ethanol precipitation. Normal control DNA was extracted from blood lymphocytes by the same method.

\section{Microsatellite Analysis}

Microsatellite markers and their approximate positions are shown in Figure 1. The sequences and location of the markers were obtained from the Genome Database (http://gdbwww.gdb.org/gdb/gdbtop.html), from the data base of the Whitehead Institute for Biomedical Research (http://www-genome.wi.mit.edu/) and from GeneMap'99 (http://www.ncbi.nlm.nih.gov/ genemap/). For amplification of microsatellite locus D8S504, we used the primers described by Sunwoo et al (1999). Matched normal and tumor DNA samples were amplified in $10 \mu \mathrm{l}$ reactions with $50 \mathrm{ng}$ of genomic DNA, $50 \mathrm{~mm} \mathrm{KCl,} 10 \mathrm{~mm}$ Tris- $\mathrm{HCl}(\mathrm{pH} 8.3)$, $1.5 \mathrm{~mm} \mathrm{MgCl}_{2}, 200 \mu \mathrm{M}$ each dNTP, 5 pmol Cy5-labeled forward primer, 5 pmol reverse primer, and $0.5 \cup$ Taq DNA polymerase (Gibco BRL, Eggenstein, Germany). After 2 minutes of denaturation at $94^{\circ} \mathrm{C}$, the PCR mixes were subjected to the following conditions: 40 seconds at $94^{\circ} \mathrm{C}, 30$ seconds at $55^{\circ} \mathrm{C}$, and 40 seconds at $72^{\circ} \mathrm{C}$ for 28 cycles, with a delayed last step for 10 minutes at $72^{\circ} \mathrm{C}$ in a PTC200 thermal cycler (MJ Research Inc., Watertown, Massachusetts). Before loading, $20 \mu \mathrm{l}$ of $50 \mathrm{~mm}$ EDTA stop solution and $5 \mathrm{mg} / \mathrm{ml}$ of Dextran Blue 2000 in 100\% deionized formamide were added, and the samples were denatured at $95^{\circ} \mathrm{C}$ for 2 minutes and immediately cooled on ice for 1 minute. Analysis was carried out on an automated DNA analyzer (ALFexpressll, Amersham/ Pharmacia Biotech, Freiburg, Germany). The 6\% denaturing polyacrylamide gels (acrylamide:bisacrylam- ide $=19: 1)$ were run at $400 \mathrm{~V}, 55 \mathrm{~mA}$, and $30 \mathrm{~W}$ in $1 \mathrm{x}$ TBE buffer (445 mM Tris; $445 \mathrm{mM}$ boric acid; $13 \mathrm{mM}$ EDTA, pH 8.0) at a constant gel temperature of $55^{\circ} \mathrm{C}$. The collected raw data were evaluated using the Fragment Manager software (FM 1.2; Amersham/ Pharmacia Biotech).

\section{Acknowledgements}

The authors would like to thank Drs. Tilman Kälble and Peter Alken for providing the fresh tissue samples and clinicopathologic data.

\section{References}

Baud E, Catilina P, Boiteux J, and Bignon Y (1998). Human bladder cancers and normal bladder mucosa present the same hot spot of heterozygous chromosome 9 deletion. Int $\mathrm{J}$ Cancer 77:821-824.

Gustafson CE, Wilson PJ, Lukeis R, Baker E, Woolatt R, Annab L, Hawke L, Barrett JC, and Chevenix-Trench G (1996). Functional evidence for a colorectal cancer tumor suppressor gene at chromosome $8 \mathrm{p} 22-23$ by monochromosome transfer. Cancer Res 56:5238-5245.

Hovey RM, Chu L, Balazs M, DeVries S, Moore D, Sauter G, Carroll PR, and Waldman FM (1998). Genetic alterations in primary bladder cancers and their metastases. Cancer Res 58:3555-3560.

Ishwad CS, Shuster M, Bockmühl U, Thakker N, Shah P, Toomes C, Dixon M, Ferrell RE, and Gollin SM (1999). Frequent allelic loss and homozygous deletion in chromosome band 8p23 in oral cancer. Int J Cancer 80:25-31.

Kallioniemi A, Kallioniemi OP, Citro G, Sauter G, DeVries S, Kerschmann R, Carroll P, and Waldman F (1995). Identification of gains and losses of DNA sequences in primary bladder cancer by comparative genomic hybridization. Genes Chromosomes Cancer 12:213-219.

Knowles MA (1999). Identification of novel bladder tumor suppressor genes. Electrophoresis 20:269-279.

Knowles MA, Shaw ME, and Proctor AJ (1993). Deletion mapping of chromosome 8 in cancers of the urinary bladder using restriction fragment length polymorphisms and microsatellite polymorphisms. Oncogene 8:1357-1364.

Ohgaki K, lida A, Ogawa O, Kubota Y, Akimoto M, and Emi M (1999). Localization of tumor suppressor gene associated with distant metastases of urinary bladder cancer to a $1 \mathrm{Mb}$ interval on 8p22. Genes Chromosomes Cancer 25:1-5.

Orlow I, Lianes P, Lacombe L, Dalbagni G, Reuter VE, and Cordon-Cardo C (1994). Chromosome 9 allelic losses and 
microsatellite alterations in human bladder tumors. Cancer Res 54:2848-2851.

Perinchery G, Bukurov N, Nakajima K, Chang J, Hooda M, Oh BR, and Dahiya R (1999). Loss of two new loci on chromosome 8 (8p23 and 8q12-13) in human prostate cancer. Int J Oncol 14:495-500.

Pineau P, Nagai H, Prigent S, Wei Y, Gyapay G, Weissenbach J, Tiollais $P$, Buendia MA, and Dejean A (1999). Identification of three distinct regions of allelic deletions on the short arm of chromosome 8 in hepatocellular carcinoma. Oncogene 18: 3127-3134.

Richter J, Beffa L, Wagner U, Schraml P, Gasser TC, Moch H, Mihatsch MJ, and Sauter G (1998). Patterns of chromosomal imbalances in advanced urinary bladder cancer detected by comparative genomic hybridization. Am J Pathol 153:16151621.

Richter J, Jiang F, Görög JP, Sartorius G, Egenter C, Gasser TC, Moch H, Mihatsch MJ, and Sauter G (1997). Marked genetic differences between $\mathrm{pTa}$ and $\mathrm{pT} 1$ papillary bladder cancer detected by comparative genomic hybridization. Cancer Res 57:2860-2864.

Richter J, Wagner U, Schraml P, Maurer R, Alund G, Knönagel H, Moch H, Mihatsch MJ, Gasser TC, and Sauter G (1999). Chromosomal imbalances are associated with a high risk of progression in early invasive (pT1) urinary bladder cancer. Cancer Res 59:5687-5691.

Scholnick SB, Haughey BH, Sunwoo JB, el-Mofty SK, Baty JD, Piccirillo JF, and Zequeira MR (1996). Chromosome 8 allelic loss and the outcome of patients with squamous cell carcinoma of the supraglottic larynx. J Natl Cancer Inst 88:1676-1682.

Simon R, Bürger H, Brinkschmidt C, Böcker W, Hertle L, and Terpe HJ (1998). Chromosomal aberrations associated with invasion in papillary superficial bladder cancer. J Pathol 185:345-351.
Stadler WM, Sherman J, Bohlander SK, Roulston D, Dreyling H, Rukstalis D, and Olopade Al (1994). Homozygous deletion within chromosome bands 9p21-22 in bladder cancer. Cancer Res 54:2060-2063.

Sunwoo JB, Sun PC, Gupta VK, Schmidt AP, el-Mofty S, and Scholnick SB (1999). Localization of a putative tumor suppressor gene in the subtelomeric region of chromosome $8 \mathrm{p}$. Oncogene 18:2651-2655.

Takle LA and Knowles MA (1996). Deletion mapping implicates two tumor suppressor genes on chromosome $8 p$ in the development of bladder cancer. Oncogene 12:1083-1087.

Wagner U, Bubendorf U, Gasser TC, Moch H, Görög JP, Richter J, Mihatsch MJ, Waldman FM, and Sauter G (1997). Chromosome $8 p$ deletions are associated with invasive tumor growth in urinary bladder cancer. Am J Pathol 151:753759 .

Wright K, Wilson PJ, Kerr J, Do K, Hurst T, Khoo SK, Ward B, and Chevenix-Trench G (1998). Frequent loss of heterozygosity and three critical regions on the short arm of chromosome 8 in ovarian adenocarcinomas. Oncogene 17:11851188.

Wu CL, Roz L, Sloan P, Read AP, Holland S, Porter S, Scully C, Speight PM, and Thakker N (1997). Deletion mapping defines three discrete areas of allelic imbalance on chromosome arm $8 p$ in oral and oropharyngeal squamous cell carcinomas. Genes Chromosomes Cancer 20:347-353.

Zhao J, Richter J, Wagner U, Roth B, Schraml P, Zellweger T, Ackermann D, Schmid U, Moch H, Mihatsch MJ, Gasser TC, and Sauter G (1999). Chromosomal imbalances in noninvasive papillary bladder neoplasms (pTa). Cancer Res 59: 4658-4661. 